\title{
Electrical characterization of GO at different pH towards MCF7 and MCF10a: preliminary result
}

\begin{abstract}
The intracellular $\mathrm{pH}$ of cancerous cell is commonly acidic while the intracellular $\mathrm{pH}$ of normal cell is neutral. The objective of this study is to study the electrical characterization in terms of resistance between the $\mathrm{pH}$ of sensing material with the intracellular $\mathrm{pH}$ of the cells. Three different $\mathrm{pH}$ of Graphene Oxide (GO) were used as a solvent to analyze their interaction towards breast cancer cells (MCF7) and breast normal cells (MCF10a). GO which produced by Hummer's method was used due to their solubility and biocompatibility characteristics which easily diffuse through the cell. In this experiment, the characteristics of GO were analyzed and confirmed by using Atomic Force Microscopy (AFM) and Fourier Transform Infrared spectroscopy (FTIR). In order to measure the resistance of MCF7 and MCF10a cells after treated with GO for 24 hours, gold electrodes with $10 \varepsilon$-gaps of interdigitated electrodes (IDEs) were used. The results were obtained for three periods of time which were immediate, 5 minutes and 10 minutes after the treated cells being exposed at room temperature. The results show that the resistance of MCF10a cells increased after treated with higher $\mathrm{pH}$ of GO which is $\mathrm{pH} 7$ and the resistances of the MCF7 cells decreased as the $\mathrm{pH}$ of $\mathrm{GO}$ increased to $\mathrm{pH} 7$. Finally, the viable cells were calculated by using haemocytometer in order to prove that the increased of the resistances were due to the increased number of viable cells.
\end{abstract}

Keyword: Graphene oxide; pH; Interdigitated electrode; MCF7; MCF10a 